\title{
Experimental Study on Suppression of Methane Explosion Containing Obstacles with Ultra-fine Water Mist
}

\author{
H. L. XU, Y. LI, P. ZHU, W. X. QIN, X. S. WANG' \\ State Key Lab. of Fire Science, University of Science \& Technology of China \\ Hefei 230026, P. R. China
}

\begin{abstract}
The effects of obstacles on methane explosion inside a narrow space and its suppression by ultra-fine water mist are investigated experimentally. Two PCB pressure transducers and two E12-1-C-U fast response thermocouples are used to obtain the explosion pressure and temperature, respectively. A Fastcam Ultima APX high speed video camera is used to visualize the process of methane explosion with the influence of obstacles and ultra-fine water mist. The results show that the explosion would be strengthened by the obstacles, while the further strengthening occurs to the cases where the obstacles are farther from the ignition electrode. In addition, the more the obstacles are, the stronger the explosion strengthening will be. The reinforcement effect on gas explosion of the square ring is a little stronger than the column one. The suppression of methane gas explosion containing obstacles with ultra-fine water mist is very effective.
\end{abstract}

KEYWORDS: gas explosion, explosion overpressure, explosion suppression, water mist

\section{NOMENCLATURE}

\begin{tabular}{|c|c|c|c|}
\hline$Q_{v}, d Q$ & blasting heat value of explosive & $a$ & velocity of sound \\
\hline$d E$ & $\begin{array}{l}\text { internal energy data of combustion } \\
\text { product }\end{array}$ & $A_{t}$ & $\begin{array}{l}\text { the area of the perpendicular direction of } \\
\text { gas flow }\end{array}$ \\
\hline$V_{w}$ & volume of water mist & $V$ & the initial volume of the gas cloud \\
\hline$S_{o}$ & cross-section area of explosion vessel & $p_{0}$ & initial pressure of gas cloud \\
\hline$S_{l}$ & cross-section area of obstacle & $\rho_{0}$ & initial density of gas cloud \\
\hline$\rho$ & density of the gas & $r_{0}$ & specific heat ratio \\
\hline$u$ & gas flow rate & $P_{m}$ & final pressure \\
\hline$r$ & distance of the obstacle from the ignition & $P_{0}$ & initial pressure \\
\hline$t$ & time & $P$ & instantaneous pressure \\
\hline$p$ & explosion pressure(gauge pressure) & $L$ & length of explosion vessel \\
\hline$k_{1}, k_{2}$ & disturbance factor & $\alpha K_{r}$ & apparent reaction rate \\
\hline
\end{tabular}

\section{INTRODUCTION}

Coal is accounting for $70 \%$ of China's current energy consumption, which has made an indelible contribution for the country's economic development. However, more than $90 \%$ coal mines in China are being exploited at the risk of gas explosion, which have caused great irreversible environmental pollution and casualty losses. Therefore, the research on gas explosion suppression has scientific and practical significances to prevent and reduce methane gas explosions [1].

Being considered as an environmental friendly, efficient and economical fire extinguishing technology, water mist has been applied for fire suppression in many areas [2-8]. The research on suppression of explosion with water mist has also been done in recent years. For instance, the suppression of blast waves from explosives using water mist, chemical and physical processes of explosion suppression with ultra-fine water mist, suppression of TNT explosion with ultra-fine water mist were studied [9-11]. Recently, the experimental investigation on different concentrations of methane explosion and methane-coal dust mixture explosion suppression by different volumes of ultra-fine water mist were carried out to study the characteristic of mixture explosion and its suppression by water mist [12-15]. Meanwhile, a computational model of gas 
explosion in a constant volume bomb is built, the mole fraction profiles of reactants, some selected free radicals, catastrophic gases in the process of gas explosion, the inhibition mechanisms of water on gas explosion and the formation of catastrophic gases were analyzed [16].

In previous research, obstacle is considered for their intense effects on explosion, a validated Large Eddy Simulation model of unsteady premixed flame propagation is used to study the phenomenology underlying vented gas explosions in the presence of obstacles. In this research, methane-air mixtures of various compositions, and obstacles with different area blockage ratios and shapes were investigated [17]. In addition, the interaction of the cloud (debris) with a solid beam located at some distance from the explosion where the influence of different parameters like the value of the pressure of the explosion, the particle size, the number of particles and the obstacle location were investigated [18]. Experiments on the effects of flame interactions with different multiple obstacles within chambers of different $\mathrm{L} / \mathrm{D}$ ratios were performed. Five chambers were employed to examine the flame interaction with multiple bars in each chamber [19]. In the research progress of explosion with obstacles, an assessment of different sub-grid scale (sgs) combustion models proposed for large eddy simulation (LES) of steady turbulent premixed combustion was performed to identify the model that well predicted unsteady flame propagation. It was found that all sgs combustion models were able to reproduce qualitatively the experiments in terms of step of flame acceleration and deceleration around each obstacle, and shape of the propagating flame [20]. The predictive ability between existing models on explosion venting, such as the NFPA, Molkov and Yao equations, were examined against experimental data of peak pressures obtained in various chambers with internal obstacles [21].

As mentioned above, there are many studies focus on gas ignition, gas explosion and even the effects of obstacles on gas explosion. However, there are only a few literatures related to gas explosion suppression with water mist while obstacle effects being considered [22-27]. In fact, about methane gas explosion in coal mine areas, there are many kinds of obstacles, such as pillars, balk frames, etc., which will influence the explosion itself and its prevention efficiencies. Therefore, experimental studies on methane gas explosion suppression by ultra-fine water mist with the effects of different kinds of obstacles are carried out in this paper. Different methane gas concentrations, obstacles with different shapes and geometry size, and different volume of ultrafine water mist are considered.

\section{EXPERIMENTAL APPARATUS}

Figure 1 shows the schematic diagram of experiment apparatus. The whole system consists of the following parts: a) explosion vessel, b) pulse ignition system, c) data acquisition system, d) gas supply system, e) ultrasonic atomizer and $\mathrm{f}$ ) high-speed video camera. The explosion vessel is about $600 \mathrm{~mm}$ long with a square section of $100 \mathrm{~mm} \times 100 \mathrm{~mm}$. Two opposite sides of vessel wall are made of stainless steel with $6 \mathrm{~mm}$ thick and $4 \mathrm{~mm}$ thick, respectively. A couple of ignition electrodes, two E12-1-C-U type fast response thermocouples with microsecond response time, two PCB piezotronic pressure transducers and a pressure release hole are distributed on the $6 \mathrm{~mm}$ thick stainless steel plate with. Obstacles are fixed on the other stainless steel plate at interval of $100 \mathrm{~mm}$ from the location $190 \mathrm{~mm}$ away from the igniter. The other two walls of the vessel are made of transparent acryl glass that is convenient for optical observation. Both the ends of the vessel are sealed by flanges and gaskets. A D08-3B/ZM mass flow controller is used to adjust the gas flow rate. The ignition system is the SMC-1R1 high voltage pulse igniter with a continuous adjustable voltage range of $0-10 \mathrm{KV}$, i.e., the output energy range is $0-900 \mathrm{~mJ}$. The ultra-fine water mist is generated by an ultrasonic atomizer. A Fastcam Ultima APX high speed video camera worked with $1000 \mathrm{fps}$ frame rate and $1280 \times 256$ pixels resolution is used to visualize the process of the explosion suppression.

As shown in Fig. 2, two types of obstacles, such as cylinder and square rings are considered in this study. The cylinder is $84 \mathrm{~mm}$ high and with diameter of $27 \mathrm{~mm}$, the external side length of the square ring is $84 \mathrm{~mm}$ while its internal side length is $70 \mathrm{~mm}$. The obstacle is fixed on a base stainless steel plate, which can be well fixed with four screws on the $4 \mathrm{~mm}$ thick stainless steel plate of the explosion vessel. Table 1 gives the cases information which related to the obstacles setting. The blocking rate, $\mathrm{S}_{\mathrm{k}}$, of the two types obstacles are both $30 \%$, which could be estimated as:

$S_{k}=\frac{S_{l}}{S_{o}} \times 100 \%$

During the whole experiments, the environmental temperature is $5 \sim 10{ }^{\circ} \mathrm{C}$, the initial pressure is $1.05 \mathrm{~atm}$, the output energy of ignition electrode is about $380 \mathrm{~mJ}$. 


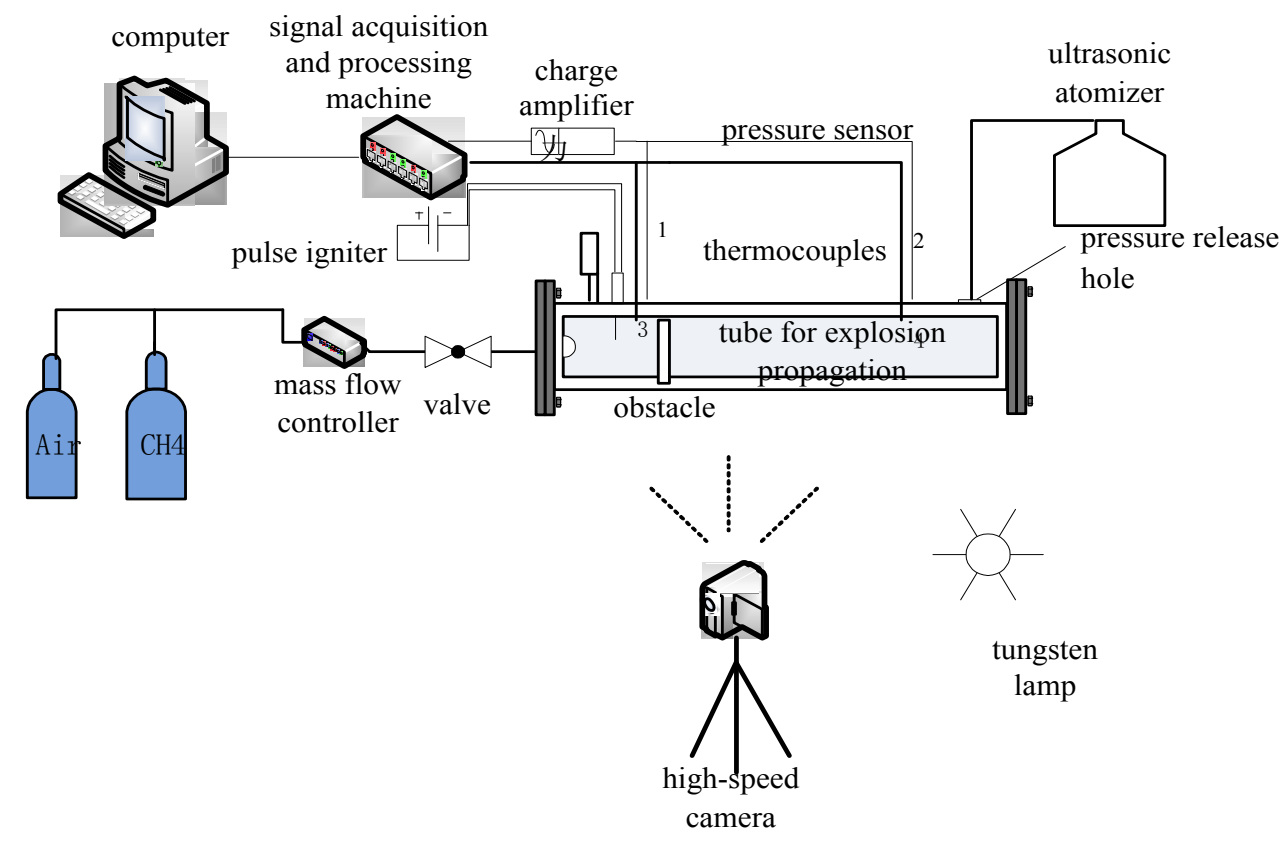

Fig. 1. Experimental apparatus of methane explosion with obstacles suppression by ultra-fine water mist

Table 1. Cases related to the obstacle's number and settings

\begin{tabular}{cccl}
\hline $\begin{array}{c}\text { Type of obstacle } \\
\text { setting }\end{array}$ & $\begin{array}{c}\text { Shape of the } \\
\text { obstacle }\end{array}$ & $\begin{array}{c}\text { Number of the } \\
\text { obstacle }\end{array}$ & Location of the obstacle setting \\
\hline Type A & $\begin{array}{l}\text { cylinder } \\
\text { cylinder }\end{array}$ & 1 & $190 \mathrm{~mm}$ away from the igniter \\
Type B & cylinder & 2 & $\begin{array}{l}290 \mathrm{~mm} \text { away from the igniter } \\
\text { Type C }\end{array}$ \\
Type D & square ring & 2 & $\begin{array}{l}\text { igniter, respectively } \\
\text { i90mm and } 290 \mathrm{~mm} \text { away from the } \\
\text { igniter, respectively }\end{array}$ \\
\hline
\end{tabular}
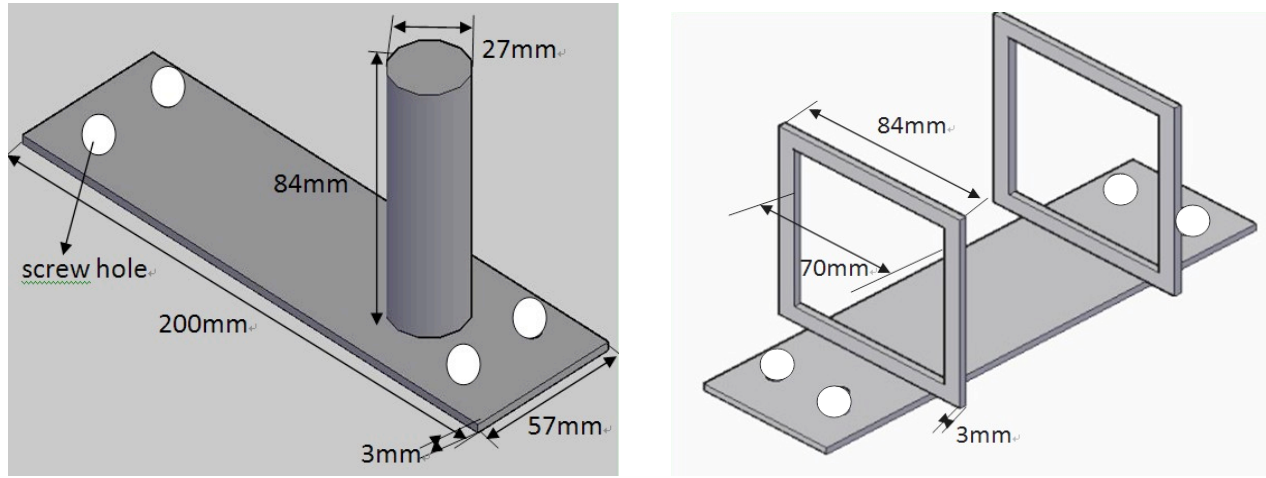

Fig. 2. Schematic diagram of the two types of the obstacles

In order to discuss the physical mechanisms by which the water mist is able to mitigate the explosion. The droplets features of ultrafine water mist is measured by the Particle Master IMI produced by LaVision Co. The IMI pattern and the size distribution of the ultrafine water mist are shown in Fig. 3 and Fig.4, while Table 2 gives the different mean diameters of the water mist diameter. From the measure results, the most of the ultrafine water mist droplets are less than $10 \mu \mathrm{m}$. The droplets of ultrafine water mist have large latent heat of evaporation, that can well absorb the reaction heat emitted by mixed explosion and dilute the oxygen concentration. 


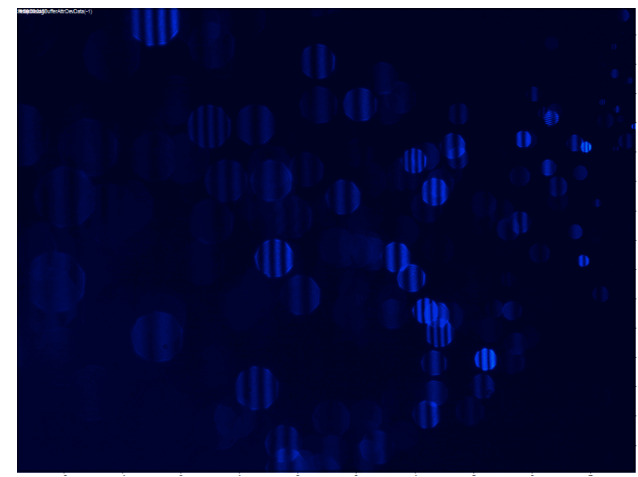

Fig. 3. IMI pattern of the ultrafine water mist droplet

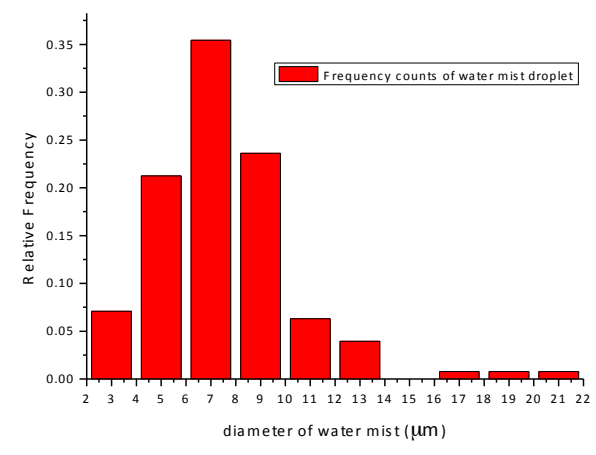

Fig. 4. Size distribution of the ultra-fine water mist

Table 2. The statistics of water mist diameter

\begin{tabular}{|c|c|}
\hline $\begin{array}{l}\text { Type of the mean } \\
\text { diameter }\end{array}$ & $\begin{array}{c}\text { The mean diameter } \\
(\mu \mathrm{m})\end{array}$ \\
\hline $\mathrm{D}_{10}$ & 7.25 \\
\hline$D_{32}$ & 9.47 \\
\hline $\mathrm{DV}_{10}$ & 2.52 \\
\hline $\mathrm{DV}_{50}$ & 7.89 \\
\hline $\mathrm{DV}_{90}$ & 17.27 \\
\hline
\end{tabular}

\section{RESULTS AND DISCUSSIONS}

The gas concentration in which the explosion is fierciest is in general a little richer than the stoichiometric concentration. The stoichiometric concentration of methane explosion is $9.48 \%$. Some studies had been performed on different concentrations of methane flame propagation in pipeline explosion, and found that the flame propagation speed and explosion pressure reached maximum value when methane concentration is in the vicinity of $10 \%$. Therefore, in this paper, seven cases of explosive concentration around optimal concentration, $6 \%, 7.5 \%, 9 \%, 10.5 \%, 12 \%, 13.5 \%$ and $15 \%$ are tested.

\subsection{Obstacles effects on the methane explosion}

Keeping other conditions unchanged, comparative experiments on methane explosion with and without obstacles are conducted. The ignition delay time is $11 \mathrm{~ms}$, maximum value of pressure measured by the two pressure sensors is treated as maximum explosion pressure and two thermocouples with microsecond response time are used to measure the temperature.

\subsubsection{Explosion temperature}

Many parameters are usually used for characterization of gas explosion, such as flame propagation speed, explosion pressure, average rate of explosion pressure rise, ignition energy and explosion temperature, etc. the temperature is essential equal to the adiabatic flame temperature.

The line chart of maximum temperature with different settings of obstacles and different concentrations of methane gas mixture is shown in Fig. 3. With obstacles, the measured maximum temperature is about $2100^{\circ} \mathrm{C}$.

As shown in Fig. 5, the explosion temperature increases with the increase of methane concentration, and decrease after they reach the maximum value where the methane concentration is about $10.5 \%$. Explosion is obviously enhanced by the obstacles. The reasons may be that after the initial deflagration, the flame moves forward and the shock wave access to the obstacles, then the gas mixture around the obstacles would be compressed and disturbed. Meanwhile, the heterogeneity of the airflow velocity would be enhanced due to the high gradient of viscous boundary layer around the obstacles, and the separate vortex groups behind the obstacles should be formed, which may cause obvious increase of gas turbulence. 


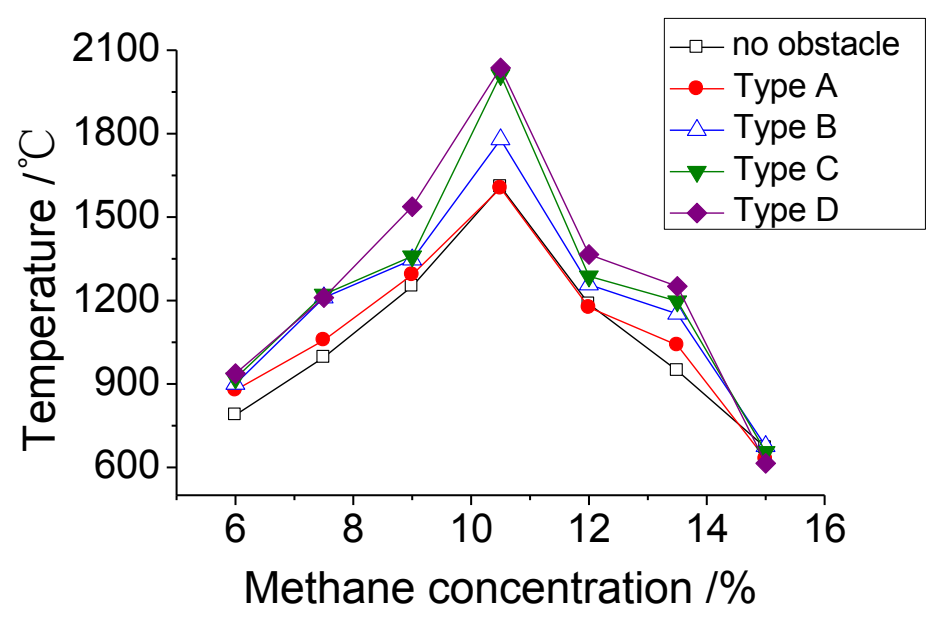

Fig. 5. Explosion temperature with different methane gas mixture concentrations and different types of obstacles

\subsubsection{Explosion pressure}

The explosion pressure can be solved by the energy equation of the combustion flame, and the mass, momentum equation of the pressure wave. If consider the flame acceleration effect by the obstacle and ignore the local changes in flame propagation path, the N-S equation will be [28]:

$\frac{\partial \rho}{\partial t}+\frac{1}{r^{2}} \frac{\partial\left(\rho u r^{2}\right)}{\partial r}=0$

$\frac{\partial u}{\partial t}+\frac{u \partial u}{\partial r}=-\frac{1}{\rho} \frac{\partial p}{\partial r}-\frac{\partial \tau_{r r}}{\partial r}$

where $\frac{\partial \tau_{r r}}{\partial r}$ is the disturbance caused by the obstacle, and it can be expressed as [29]:

$\frac{\partial \tau_{r r}}{\partial r}=k_{1} \frac{\partial u}{\partial t}+k_{2} \frac{u^{2}}{2}$

where $k_{1} \frac{\partial u}{\partial t}$ is the inertial drag force on the gas cloud by the obstacle, $k_{2} \frac{u^{2}}{2}$ is the shape drag of obstacle, while

$k_{1}=C_{m} V_{b}, k_{2}=C_{d} A_{t} / V$. Since the blasting process is very fast, the pressure wave propagation process can be regarded as adiabatic process, and then the differential form of the process equation is:

$\frac{1}{\rho} \frac{\partial p}{\partial r}=\frac{p_{o}^{1 / r_{0}}}{\rho_{0}} \frac{r_{0}}{r_{0}-1} \frac{\partial p^{r_{0}-1 / r_{0}}}{\partial r}$

Take above equations into Eq. 6, the following equation can be obtained:

$k_{1} \int \frac{\partial u}{\partial t} d r+\int \frac{\partial u}{\partial t} d r+\int \frac{u \partial u}{\partial t} d r+k_{2} \int \frac{1}{2} u^{2} d r=-\frac{p_{o}^{1 / r_{0}}}{\rho_{o}} \frac{r_{0}}{r_{0}-1} \int \frac{\partial p^{\left(r_{0}-1\right) / r_{0}}}{\partial r} d r$ 
In the case of deflagration, combustion rate is very small compared to the local speed of sound, the gas density change is slight in front of the fire flow field, so to simplify the mass conservation equation, the density can be regarded as a constant, i.e., $\frac{\partial \rho}{\partial t}=0, \frac{\partial \rho}{\partial r}=0$. Take these two parameters into Eq. (2), the velocity field can be expressed as:

$$
\begin{aligned}
& u(r)=u\left(R_{f}\right) R_{f}^{2} / r^{2} \\
& \frac{\partial u}{\partial t}=\frac{R_{f}^{2}}{r^{2}} \frac{d u\left(R_{f}\right)}{d t}+u\left(R_{f}\right) \frac{2 R_{f}}{r^{2}} \frac{d R_{f}}{d t}
\end{aligned}
$$

Where, $R_{f}$ is the distance of the flame front from the ignition point. Eq. (8) can be integrated as:

$$
\left(1+k_{1}\right)\left[\frac{R_{f}^{2}}{r} \frac{d u\left(R_{f}\right)}{d t}+2 \frac{R_{f}}{r} \frac{d R_{f}}{d t} u\left(R_{f}\right)\right]-\frac{1}{2} \frac{R_{f}^{4}}{r^{4}} u^{2}\left(R_{f}\right)+\frac{1}{6} \frac{R_{f}^{4}}{r^{3}} u^{2}\left(R_{f}\right)=\frac{p_{o}^{1 / r_{0}}}{\rho_{o}} \frac{r_{0}}{r_{0}-1} p^{\left(r_{0}-1\right) / r_{0}}+C_{1}
$$

Where $C_{1}$ is an integration constant, and when $r \rightarrow \infty, \mathrm{p}=\mathrm{p}_{0}, C_{1}$ can be expressed as:

$$
C_{1}=-\frac{p_{0}}{\rho_{0}} \frac{r_{0}}{r_{0}-1}
$$

Then, Eq. (9) will be:

$$
\left(1+k_{1}\right)\left[\frac{R_{f}^{2}}{r} \frac{d u\left(R_{f}\right)}{d t}+2 \frac{R_{f}}{r} \frac{d R_{f}}{d t} u\left(R_{f}\right)\right]-\frac{1}{2} \frac{R_{f}^{4}}{r^{4}} u^{2}\left(R_{f}\right)+\frac{1}{6} \frac{R_{f}^{4}}{r^{3}} u^{2}\left(R_{f}\right)=\frac{a^{2}}{r_{0}-1}\left[\left(\frac{p}{p_{0}}\right)^{\left(r_{0}-1\right) / r_{0}}-1\right]
$$

In addition, considering the flame speed, $S_{f}=\frac{d R_{f}}{d t}, u\left(R_{f}\right)$ can be expressed as:

$$
u\left(R_{f}\right)=\frac{d R_{f}}{d t}-S_{u}=S_{f}-S_{u}
$$

where $\mathrm{S}_{\mathrm{u}}$ is laminar burning velocity of gas, explosion flame velocity is $\mathrm{E}$ times laminar burning velocity, i.e., $S_{f}=E S_{u}$. Generally, E=1.6-2.2, then:

$u\left(R_{f}\right)=(E-1) S_{u}$

Substituting Eq. 16 into Eq. 14, follow equation will be obtained:

$$
\frac{p}{p_{0}}=\left[\frac{r_{0}-1}{a^{2}}(E-1)\left[\left[\frac{R_{f}^{2}}{r} \frac{d S_{u}}{d t}+2 \frac{R_{f}}{r} E S_{u}^{2}\right]+\left(1+k_{1}\right)-\frac{1}{2} \frac{R_{f}^{4}}{r^{4}}(E-1) S_{u}^{2}-\frac{1}{6} k_{2} \frac{R_{f}^{4}}{r^{3}}(E-1) S_{u}^{2}\right]+1\right]^{r_{0} /\left(r_{0}-1\right)}
$$

Substituting the parameters related to type D obstacle into Eq. (14), the explosion pressure (gauge pressure) will be estimated to $\mathrm{p}=108 \mathrm{KPa}$. The line chart of maximum explosion pressure (gauge pressure) with different settings of obstacles and different concentrations of methane gas mixture is shown in Fig. 6 . To the cases with obstacles, the measured maximum pressure is about $170 \mathrm{kPa}$, that is higher than the estimated one. 
As shown in Fig.6, the explosion pressure increase with the increase of methane concentration, and decrease after they reach the maximum value where the methane concentration is about $10.5 \%$, which is very similar with that of temperature. In addition, the effects of the obstacles with type $\mathrm{B}$, type $\mathrm{C}$ and type $\mathrm{D}$ setting are much stronger than type A setting, while the enhancement of the later two are more effective than the former one. This indicates that both of the number and setting locations of the obstacles are key factors which will mainly influence the explosion. When obstacle is set in the front of the flame, the high gradient viscous boundary layer would form in the vicinity of the obstacle, and result in turbulence. Small-scale turbulence increases the heat and mass exchange rate, large scale turbulent distorts the flame front and improves the flame area. Hence, the increased turbulence burning area causes flame acceleration and strengthens turbulence. These factors can improve the burning rate and thus speed up the rate of pressure rise.

Meanwhile, under the experimental conditions, the more the obstacles are, or the farther the obstacles are set away from the igniter, the stronger the explosion will be. When the explosion pressure wave propagates in the vessel, obstacles with sharp edges and square corners are more easily to form disorderly vortex in the vicinity of it, so the reinforcement effect to explosion by the square ring obstacles is more apparent than that by the cylinder obstacles although they have same blockage ratios.

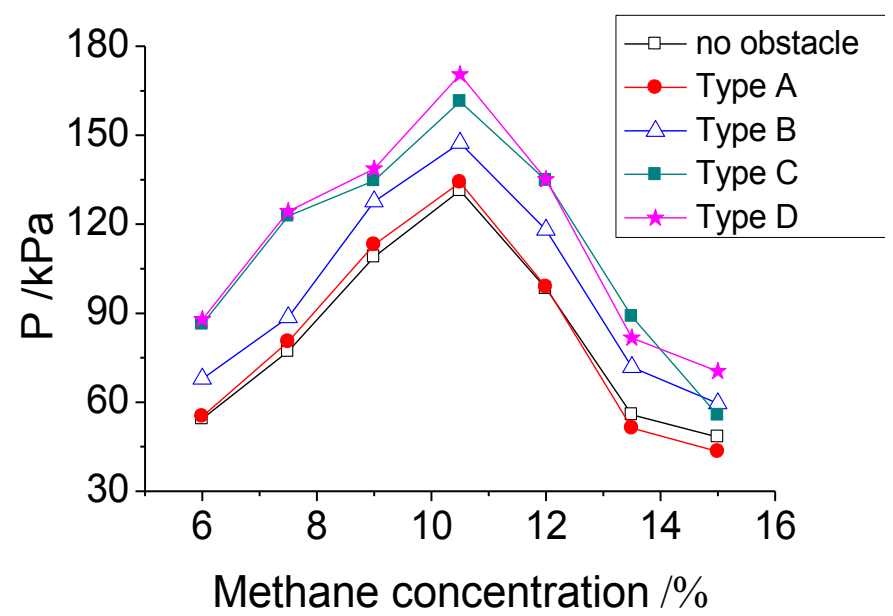

Fig. 6. Explosion pressure (gauge pressure) with different methane gas concentrations and different types of obstacles

The rate of pressure rise is an important parameter to measure the blast wave rate and it is also a standard to measure explosion strength. Table 3 gives the pressure rise rate of $7.5 \%$ methane explosion with different obstacle settings.

Table 3. Pressure rise rate of $7.5 \%$ methane explosion with different obstacle settings

\begin{tabular}{lc}
\hline Type of obstacle setting & Explosion pressure rise rate $\mathbf{( k P a / s )}$ \\
\hline No obstacle & 158 \\
Type A & 190 \\
Type B & 219 \\
Type C & 318 \\
Type D & 358 \\
\hline
\end{tabular}

\subsection{Obstacles effects on the methane explosion suppression by ultra-fine water mist}

In order to study the effects of obstacles on methane explosion suppression with ultra-fine water mist and to avoid turbulence enhancement caused by ultra-fine water mist injection, an ultrasonic atomizer is used to produce low speed ultra-fine water mist, and the ignition is triggered delaying for $3 \mathrm{~s}$ until water mist well fill the explosion vessel. The droplet diameter of ultra-fine water mist is about $10 \mu \mathrm{m}$ and the rate of ultra-fine water mist generation by the ultrasonic atomizer is about $350 \mathrm{cc} / \mathrm{h}$, i.e., $0.0972 \mathrm{~mL} / \mathrm{s}$. So through controlling 
the mist generation time within $0 \mathrm{~s}, 20 \mathrm{~s}, 30 \mathrm{~s}, 40 \mathrm{~s}, 50 \mathrm{~s}$ and $60 \mathrm{~s}$, the corresponding volume of ultra-fine water mist, such as $0 \mathrm{~mL}, 1.94 \mathrm{~mL}, 2.91 \mathrm{~mL}, 3.88 \mathrm{~mL}, 4.85 \mathrm{~mL}$ and $5.82 \mathrm{~mL}$ can be filled inside the explosion vessel, respectively. That is, the volume concentration of ultrafine water mist is $0.33 \mathrm{~L} \cdot \mathrm{m}^{-3}, 0.49 \mathrm{~L} \cdot \mathrm{m}^{-3}, 0.65$ $\mathrm{L} \cdot \mathrm{m}^{-3}, 0.81 \mathrm{~L} \cdot \mathrm{m}^{-3}, 0.97 \mathrm{~L} \cdot \mathrm{m}^{-3}$, respectively.

The overpressure history of $10.5 \%$ methane explosion mitigated by ultra-fine water mist with effect of type B obstacle is shown in Fig. 7. Table 4 gives the details of maximum pressure of methane explosion mitigated by ultra-fine water mist with the effects of type B obstacle. These results are also obviously shown in Fig. 8. To the worst case of $10.5 \%$ methane explosion, the maximum explosion pressure is about $147.4 \mathrm{kPa}$ without application of ultra-fine water mist. When $0.33 \mathrm{~L} \cdot \mathrm{m}^{-3}, 0.49 \mathrm{~L} \cdot \mathrm{m}^{-3}, 0.65 \mathrm{~L} \cdot \mathrm{m}^{-3}$, and $0.81 \mathrm{~L} \cdot \mathrm{m}^{-3}$, ultra-fine water mist are applied to mitigate the explosion, the maximum explosion pressure reduce to about $134 \mathrm{kPa}, 120$ $\mathrm{kPa}, 72.9 \mathrm{kPa}$ and $40.1 \mathrm{kPa}$, i.e., the reduction is about $10 \%, 19 \%, 51 \%$ and $73 \%$, respectively. When the amount of ultra-fine water mist is $0.97 \mathrm{~L} \cdot \mathrm{m}^{-3}$, explosion does not occur to the cases with different methane concentrations. This means that the methane explosion is completely suppressed by ultra-fine water mist although the explosion is being enhanced by the obstacles.
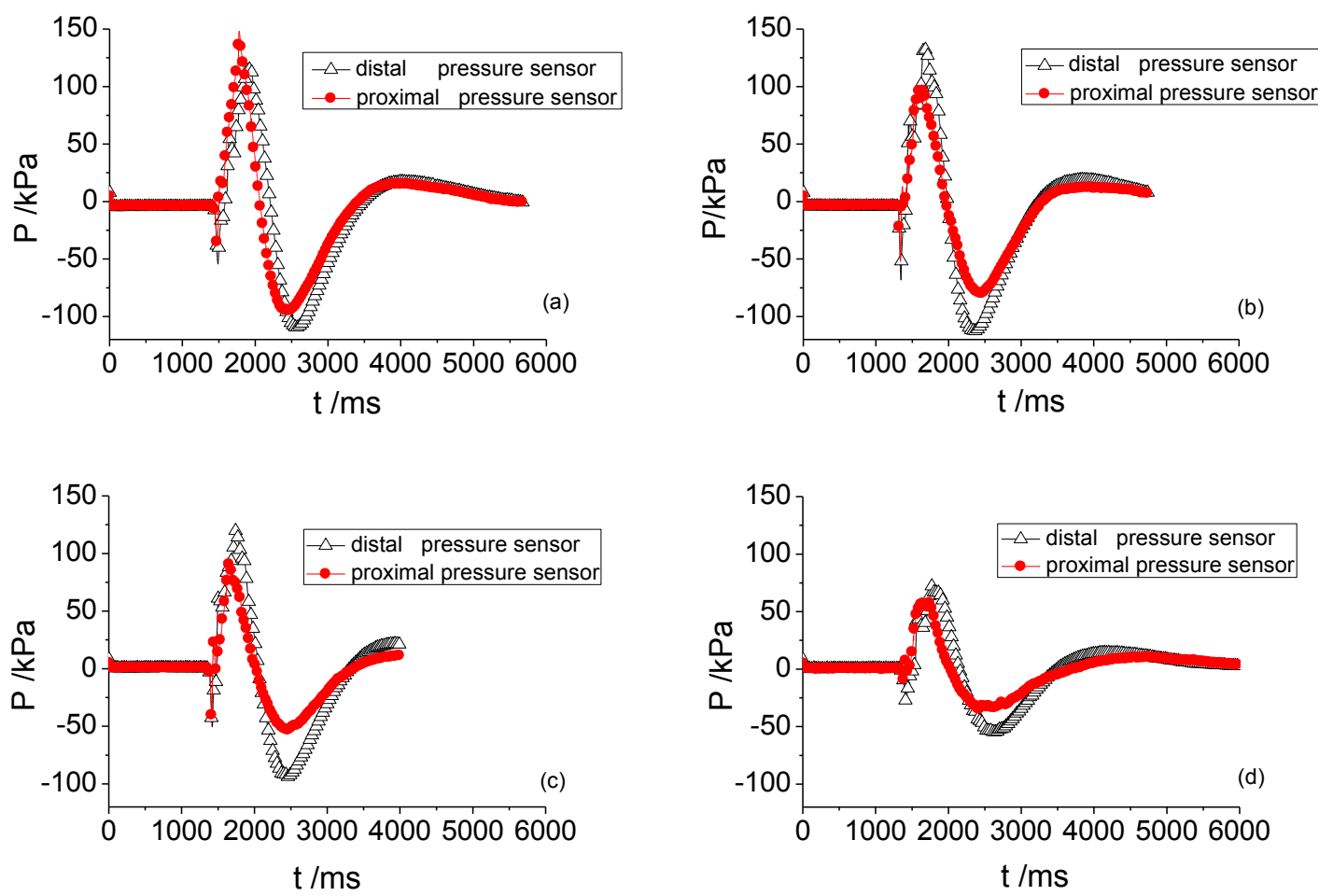

Fig. 7. Overpressure history of $10.5 \%$ methane explosion under suppression with ultra-fine water mist (affected by type B obstacle)
(a) without ultra-fine water mist
(b) with $0.33 \mathrm{~L} \cdot \mathrm{m}^{-3}$ ultra-fine water mist

(c) with $0.49 \mathrm{~L} \cdot \mathrm{m}^{-3}$ ultra-fine water mist

(d) with $0.65 \mathrm{~L} \cdot \mathrm{m}^{-3}$ ultra-fine water mist 


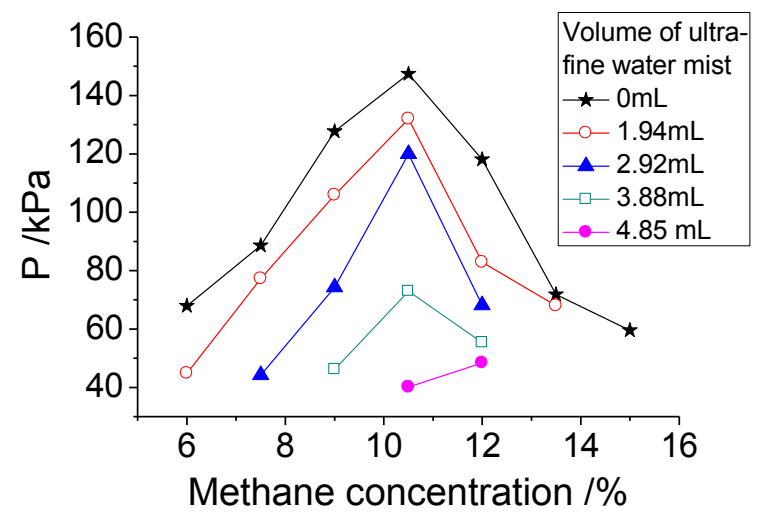

Fig. 8. Maximum pressure of methane explosion under suppression of ultra-fine water mist (affected by type B obstacle)

The maximum temperature of $10.5 \%$ methane explosion mitigated by ultra-fine water mist with different volume and affected by type B obstacle is also shown in Fig. 9 and Table 4. The results show that the effects of methane concentration and volume of water mist on methane explosion temperature are similar as their effects on methane explosion pressure.

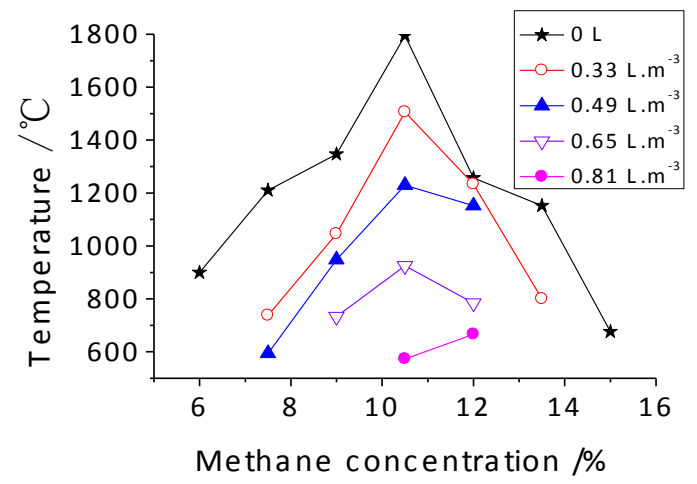

Fig. 9. Maximum temperature of methane explosion under suppression of ultra-fine water mist and affected by type B obstacle

Table 4. Maximum pressure of methane explosion under suppression of ultra-fine water mist

(affected by type B obstacle)

\begin{tabular}{|c|c|c|c|c|c|c|c|c|c|c|c|c|}
\hline \multirow{2}{*}{$\begin{array}{c}\text { Methane } \\
\text { concentration } \\
(\%)\end{array}$} & \multicolumn{2}{|c|}{$0 \mathrm{~mL}$} & \multicolumn{2}{|c|}{$0.33 \mathrm{~L} \cdot \mathrm{m}^{-3}$} & \multicolumn{2}{|c|}{$0.49 \mathrm{~L} \cdot \mathrm{m}^{-3}$} & \multicolumn{2}{|c|}{$0.65 \mathrm{~L} \cdot \mathrm{m}^{-3}$} & \multicolumn{2}{|c|}{$0.81 L \cdot m^{-3}$} & \multicolumn{2}{|c|}{$0.97 \mathrm{~L} \cdot \mathrm{m}^{-3}$} \\
\hline & $\begin{array}{l}\mathbf{P}_{1} \\
(\mathbf{k P a})\end{array}$ & $\begin{array}{l}\mathbf{P}_{2} \\
(\mathbf{k P a})\end{array}$ & $\begin{array}{l}\mathbf{P}_{1} \\
(\mathbf{k P a})\end{array}$ & $\begin{array}{l}\mathbf{P}_{2} \\
(\mathbf{k P a})\end{array}$ & $\begin{array}{l}\mathbf{P}_{1} \\
(\mathbf{k P a})\end{array}$ & $\begin{array}{l}\mathrm{P}_{2} \\
(\mathrm{kPa})\end{array}$ & $\begin{array}{l}\mathrm{P}_{1} \\
(\mathrm{kPa})\end{array}$ & $\begin{array}{l}\mathbf{P}_{2} \\
(\mathbf{k P a})\end{array}$ & $\begin{array}{l}\mathbf{P}_{1} \\
(\mathbf{k P a})\end{array}$ & $\begin{array}{l}\mathbf{P}_{2} \\
(\mathrm{kPa})\end{array}$ & $\begin{array}{l}P_{1} \\
(\mathrm{kPa})\end{array}$ & $\begin{array}{l}\mathrm{P}_{2} \\
(\mathrm{kPa})\end{array}$ \\
\hline 6 & 67.9 & 60 & 44.8 & 19.6 & - & - & - & - & - & - & - & - \\
\hline 7.5 & 88.6 & 75.7 & 77.3 & 60.2 & 44.2 & 38.6 & - & - & - & - & - & - \\
\hline 9 & 127.7 & 84.9 & 90.4 & 105.9 & 64.1 & 74.3 & 46.2 & 40 & - & - & - & - \\
\hline 10.5 & 147.4 & 115.8 & 97 & 134 & 91.8 & 120 & 57.4 & 72.9 & 40.1 & 34.8 & - & - \\
\hline 12 & 118.1 & 64.7 & 82.9 & 77.5 & 66.4 & 68.2 & 52.1 & 55.4 & 48.4 & 28.1 & - & - \\
\hline 13.5 & 71.8 & 50 & 68 & 26.1 & - & - & - & - & - & - & - & - \\
\hline 15 & 59.6 & 29 & - & - & - & - & - & - & - & - & - & - \\
\hline
\end{tabular}

Notes: $\mathrm{P}_{1}$, measured by the pressure sensor close to the ignition electrode; $\mathrm{P}_{2}$, measured by the pressure sensor away from the ignition electrode; —: explosion doesn't occur 


\subsection{Visualization of methane explosion mitigated by ultra-fine water mist}

A Fastcam Ultima APX high speed video camera is used to visualize the methane explosion suppression by ultra-fine water mist. Fig. 10 shows the typical results where the methane concentration is $9 \%$, and the type B obstacle is used. It shows that to the case with $0.33 \mathrm{~L} \cdot \mathrm{m}^{-3}$ ultra-fine water mist being pumped into the explosion propagation vessel, a bright flame with orange color appears after the ignition. This flame spreads rapidly along the vessel accompanied with loud sound and exits from the pressure release hole. To the case when the volume of ultra-fine water mist is increased to about $0.49 \mathrm{~L} \cdot \mathrm{m}^{-3}$, a flame with orange color also appears after the ignition, but its brightness and filling area are obviously weaker and small. In addition, the flame propagation velocity is lower and there is no obvious flame exists from the pressure release hole. This indicates that increase the content of ultra-fine water mist can mainly improve its efficiency of explosion suppression.

The typical results where the methane concentration is $9 \%$, and the type D obstacle is shown in Fig. 11. It shows that to the case with $0.33 \mathrm{~L} \cdot \mathrm{m}^{-3}$ ultra-fine water mist being pumped into the explosion propagation vessel, a bright orange flame spreads rapidly along the vessel accompanied with loud sound and exits from the pressure release hole. Comparing with the Fig.10, the brightness and propagation velocity with type B obstacle are obviously weaker and slower than that with type D obstacle. As shown in Fig.11, the whole flame propagation process completes in 50ms, but as shown in Fig.10, the whole flame propagation process lasts for about $260 \mathrm{~ms}$. This indicates that the square ring obstacle can intensify the explosion fiercer than the cylinder obstacle. This is coincident with the temperature and overpressure data mentioned above.

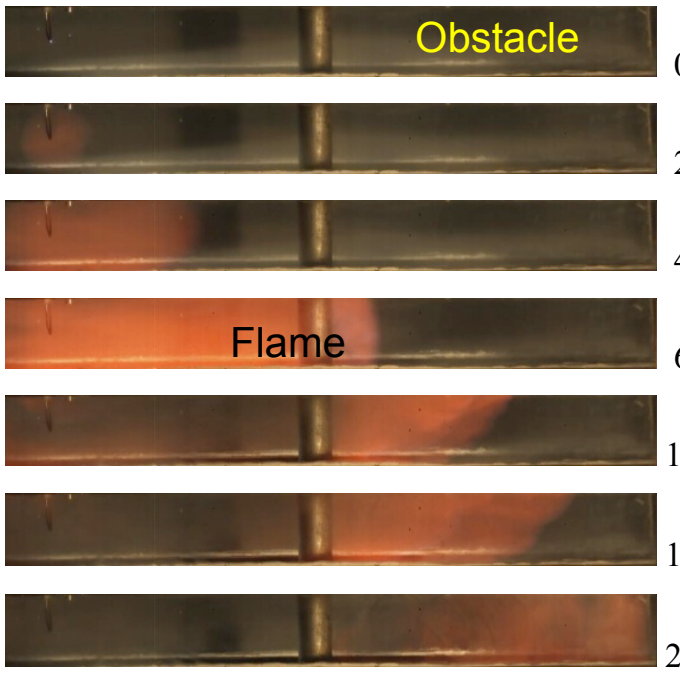

With $0.33 \mathrm{~L} \cdot \mathrm{m}^{-3}$ ultra-fine water mist

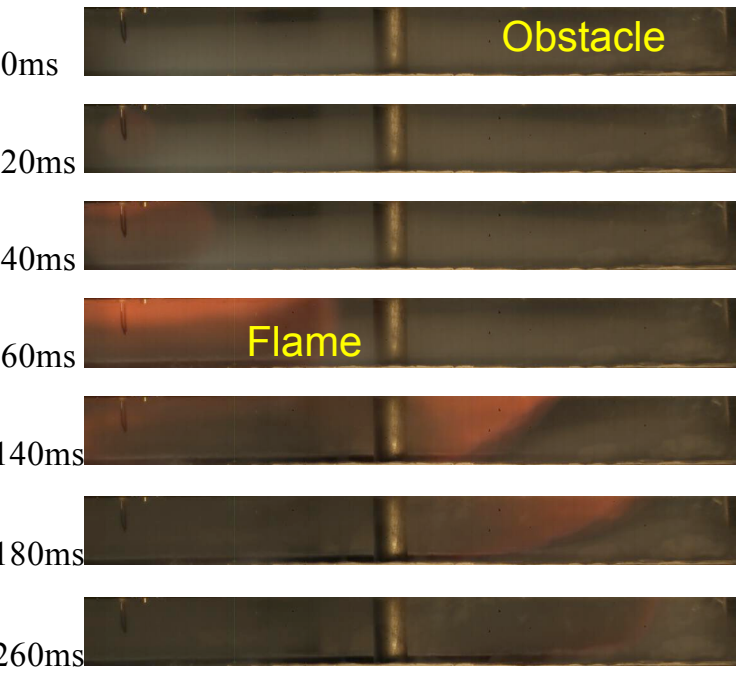

With $0.49 \mathrm{~L} \cdot \mathrm{m}^{-3}$ ultra-fine water mist

Fig. 10. Process of $9 \%$ methane explosion mitigated by ultra-fine water mist with different volumes (affected by type B obstacle) 


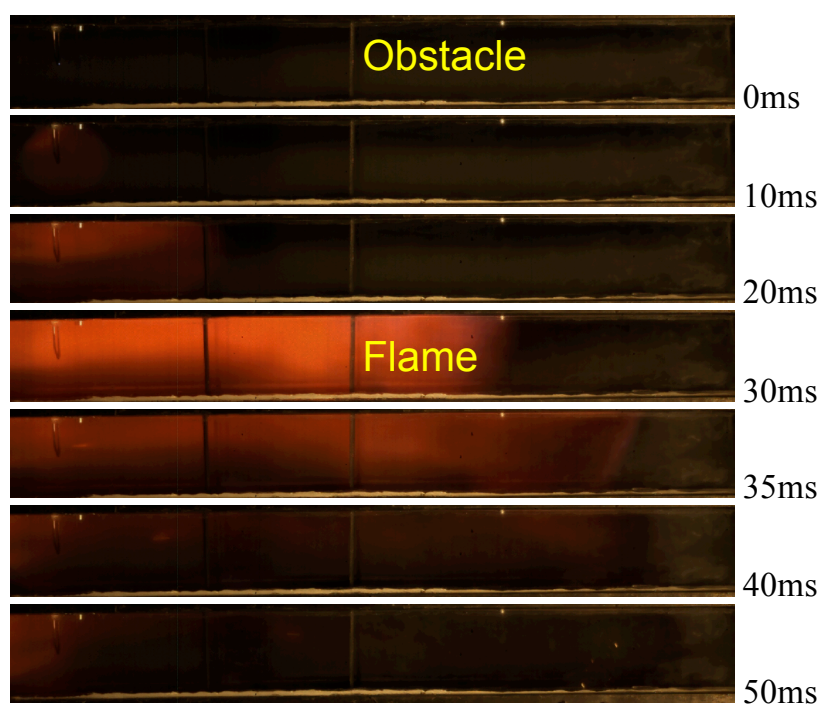

Fig.11. Process of $9 \%$ methane explosion mitigated with $0.33 \mathrm{~L} \cdot \mathrm{m}^{-3}$ ultra-fine water mist (affected by type D obstacle)

In order to further insight into the mechanism on the explosion mitigation with ultrafine water mist, the coal dust is taken as tracer particle, and the explosion flow field (just beside the type B obstacle) of methane-coal explosion mitigation with ultrafine water mist is visualized by the Flow Master PIV of LaVision system as shown in Fig.12. It obviously show that the explosion flow field without the effects of the obstacle is almost no disturbance, but the obvious disturbance occurs beside the obstacle, where many vortexes can also be seen, This can help us explain that the obstacle could strengthen the turbulence of the explosion flow field, and make the explosion fiercer.

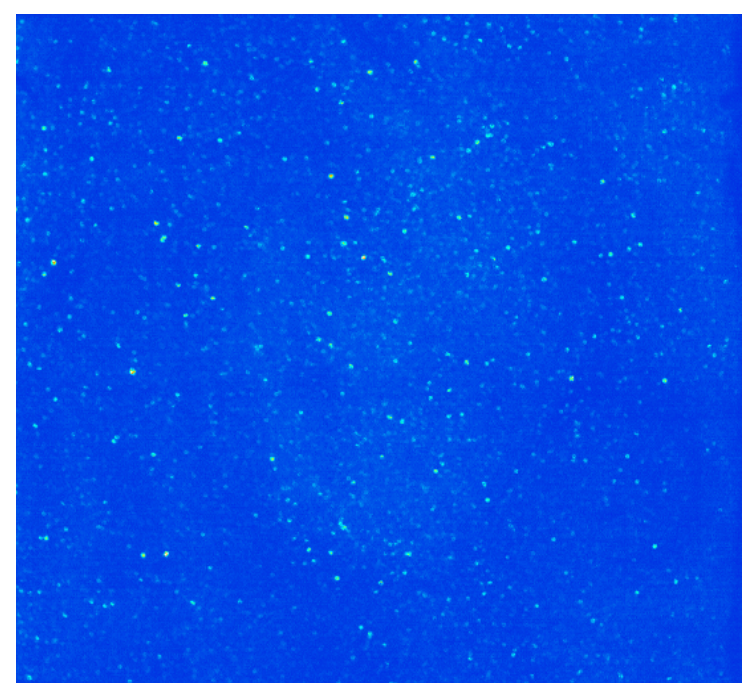

(a) without obstacle

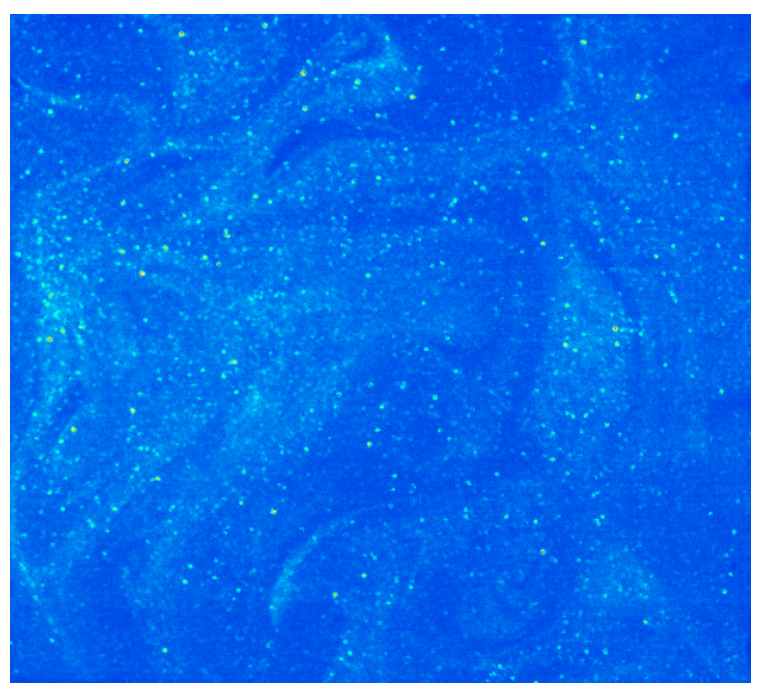

(b) type B obstacle

Fig.12. The explosion flow field with ultrafine water mist 


\section{CONCLUSIONS}

The effects of methane concentration, different obstacles and volume of ultra-fine water mist on methane explosion and its suppression by ultra-fine water mist have been investigated. Both of the maximum explosion pressure and the explosion temperature are measured and analyzed.

The gas explosion should be strengthened by the obstacles, and both of the number and setting locations of the obstacles are key factors to influence the explosion. while the strengthen effect of the obstacle located farther from the ignition electrode is more obvious. The more the obstacles are used, the stronger the explosion strengthening will be. The reinforcement effect on gas explosion of the square ring is a little stronger than the column one where they have same blockage ratios. In addition, all of the maximum explosion pressure, explosion temperature and pressure rise rate decrease with the application of ultra-fine water mist although its suppression efficiency is affected by the obstacles. The suppression of methane gas explosion containing obstacles with ultra-fine water mist is very effective, When $0.33 \mathrm{~L} \cdot \mathrm{m}^{-3}, 0.49 \mathrm{~L} \cdot \mathrm{m}^{-3}, 0.65 \mathrm{~L} \cdot \mathrm{m}^{-3}$, and $0.81 \mathrm{~L} \mathrm{~m} \mathrm{~m}^{-3}$, ultra-fine water mist are applied to mitigate the explosion, the maximum explosion pressure reduce by about $10 \%, 19 \%, 51 \%$ and $73 \%$, respectively. When the amount of ultra-fine water mist is $0.97 \mathrm{~L} \cdot \mathrm{m}^{-3}$, the methane explosion is completely suppressed by ultra-fine water mist. that is the more the ultra-fine water mist is applied, the easier the gas explosion can be mitigated. When the volume of ultra-fine water mist exceeds a certain content, the gas explosion being affected by obstacles would be completely mitigated.

The flame propagation and explosion flow field is recorded, and the images is consistent with the explosion data, further insight into the mechanism on the explosion mitigation with ultrafine water mist.

\section{ACKNOWLEDGMENTS}

The authors appreciate the support of the China National Key Basic Research Special Funds project (Grant No. 2012CB719704), The National Key Technology R\&D Program (Grant No. 2011BAK03B02).

\section{REFERENCES}

[1] Xu J. D., Xu S. L., Yang G. Y., (2004) Experimental study on mine gas explosion diffusion, Coal Science and Technology, 32:55-57(in Chinese).

[2] Ndubizu C. C., Ananth R., Tatem P. A., Motevalli V., (1998) On water mist fire suppression mechanisms in a gaseous diffusion flame, Fire Safety Journal, 31:253-276.

http://dx.doi.org/10.1016/S0379-7112(98)00007-1

[3] Prasad K., Li C., Kailasanath K., "Optimizing water-mist injection characteristics for suppression of coflow diffusion flames", 27th Symposium (Int.) on Combustion, The Combustion Institute, 1998, pp. 2847-2855. doi:10.1016/S0082-0784(98)80143-4

[4] Shimizu H., Tsuzuki M., Yamazaki Y., Koichi H. A., (2001) Experiments and numerical simulation on methane flame quenching by water mist, Journal of Loss Prevention in the Process Industries, 14: 603-608. http://dx.doi.org/10.1016/S0950-4230(01)00055-9

[5] Parra T., Castro F., Mendez C., Villafruela J. M., Rodrguez M. A.,(2004) Extinction of premixed methane-air flames by water mist, Fire Safety Journal, 39:581-560.

http://dx.doi.org/10.1016/j.firesaf.2004.05.001

[6] Huang X., Wang X. S., Liao G. X., (2011) Characterization of an effervescent atomization water mist nozzle and its fire suppression tests, Proceedings of the Combustion Institute, 33: 2573-579. doi:10.1016/j.proci.2010.06.001

[7] Huang X., Wang X. S., Jin X., Liao G. X., Qin J., (2007) Fire protection of heritage structures: use of a portable water mist system under high altitude conditions, J. of Fire Sciences, 25: 217-239. doi: $10.1177 / 0734904107069675$

[8] Cai X., Wang X. S., Liang T. S., Liao G. X., (2010) Experimental study on the effects of low ambient pressure conditions at high altitude on fire suppression with water mist. J. of Fire Sciences, 28: 441458. doi: 10.1177/0734904110361311 
[9] Schwer D. A., Kailasanath K., "Suppression of blast waves from explosives using water mist", Proceedings of the Third Joint Meeting of the US Sections of the Combustion Institute, Chicago, IL, Mar., 2003, pp.16-19.

[10] Thomas G. O., (2000) On the conditions required for explosion mitigation by water sprays, Trans IChemE, 78(Part B):339-354. http://dx.doi.org/10.1205/095758200530862

[11] Willauer H. D., Ananth R., Farley J. P., Williams F. W., (2009) Mitigation of TNT and Destex explosion effects using water mist, Journal of Hazardous Materials, 165:1068-1073. doi:10.1016/j.jhazmat.2008.10.130

[12] Xu H. L., Li Y., Zhu P., Wang X. S., Zhang H. P., (2013) Experimental study on the mitigation via an ultra-fine water mist of methane/coal dust mixture explosions in the presence of obstacles, Journal of Loss Prevention in the Process Industries, 2013(in press): doi:10.1016/j.jlp.2013.02.014.

[13] Xu H. L., Wang X. S., Gu R., Zhang H. P., (2012) Experimental study on characteristics of methanecoal dust mixture explosion and its suppression by ultra-fine water mist, Journal of Engineering for Gas Turbines and Power, 134: 061401-061406. doi: 10.1115/1.4005816

[14] Gu R., Wang X. S., Xu H. L., (2010) Experimental study on suppression of methane explosion with ultra-fine water mist, Fire safety science 19(2), 2010, pp:51-59.

[15] Qin W. X., Wang X. S., Gu R., Xu H. L., (2012) Study on methane explosion overpressure and rate of overpressure rise with suppression by ultra-fine water mist, Journal of combustion science and technology, 8: 90-95 (in Chinese).

[16] Liang Y. T., Zeng W., (2010) Numerical study of the effect of water addition on gas explosion, Journal of Hazardous Materials, 174:386-392. doi: 10.1016/j.jhazmat.2009.09.064

[17] Di Sarli V., Di Benedetto A., Russo G., (2009) Using Large Eddy Simulation for understanding vented gas explosions in the presence of obstacles, Journal of Hazardous Materials, 169:435-442. doi: 10.1016/j.jhazmat.2009.03.115

[18] Kosinska A., (2010) Interaction of debris with a solid obstacle: numerical analysis, Journal of Hazardous Materials, 177:602-612. doi: 10.1016/j.jhazmat.2009.12. 075

[19] Park D. J., Lee Y. S., Green A. R., (2008) Experiments on the effects of multiple obstacles in vented explosion chambers, Journal of Hazardous Materials, 153:340-350.

http://dx.doi.org/10.1016/j.jhazmat.2007.08.055

[20] Di Sarli V., Di Benedetto A., Russo G., (2010) Sub-grid scale combustion models for large eddy simulation of unsteady premixed flame propagation around obstacles, Journal of Hazardous Materials, 180:71-78. doi: 10.1016/j.jhazmat.2010.03.006

[21] Dal Jae Park, Young Soon Lee, Anthony Roland Green, (2010) Prediction for vented explosions in chambers with multiple obstacles, Journal of Hazardous Materials, 155:183-192. http://dx.doi.org/10.1016/j.jhazmat.2007.11.052

[22] Masri R., Ibrahim S. S, Nehzat N., Green A. R., (2000) Experimental study of premixed flame propagation over various solid obstructions, Experimental Thermal and Fluid Science, 21:109-116. http://dx.doi.org/10.1016/S0894-1777(99)00060-6

[23] Ciccarelli G., Fowler C. J., Bardon M., (2005) Effect of obstacle size and spacing on the initial stage of flame acceleration in a rough tube, Shock Waves, 14:161-166.

[24] Oh K. H., Kim H., Kim J. B., Lee S. E., (2001) A study on the obstacle-induced variation of the gas explosion characteristics, Journal of Loss Prevention in the Process Industries, 14:597-602. 
[25] Dobashi R., (1997) Experimental study on gas explosion behavior in enclosure, Journal of Loss Prevention in the Process Industries, 10:83-89. http://dx.doi.org/10.1016/S0950-4230(96)00050-2

[26] Bozhenkov S. A., Starikovskaia S. M., Starikovskii A. Y., (2003) Nanosecond gas discharge ignition of $\mathrm{H}_{2}-$ and $\mathrm{CH}_{4}-$ containing mixtures, Combustion and Flame, 133:133-146. http://dx.doi.org/10.1016/S0010-2180(02)00564-3

[27] Ibrahim S. S., Masri A. R., (2001) The effects of obstructions on overpressure resulting from premixed flame deflagration, Journal of Loss Prevention in the Process Industries, 14:213-221. http://dx.doi.org/10.1016/S0950-4230(00)00024-3

[28] Bi M. S., Yin J. Z., Wang S. L., Ding X. W., (2003) Explosion pressure calculation of flammable gas clouds with barriers, Explosion and shock waves, 23:81-85 (in Chinese).

[29] Philip R. C., Clive G. R., (1996) An analysis of the mechanisms of overpressure generation in vapor cloud explosions. Journal of Hazardous Materials, 45:27-44. http://dx.doi.org/10.1016/03043894(95)00063-1 